\title{
Transformation of Marketing Mode of Small and Medium-sized Enterprises in New Media Age
}

\author{
Wei Zheng \\ School of Business Administration, Jiangsu Institute of Commerce, Nanjing, 211168, China
}

Keywords: New media; Small and medium-sized enterprises; Marketing mode

\begin{abstract}
Considering the sustained development of modern network technology, more and more new media are changing the marketing and transmission mode in the modern society. Small and medium-sized enterprises should attach more importance to the great influence of new media in marketing communication so as to innovate the marketing mode constantly and occupy a larger consumer market. This paper discusses connotations of new media marketing, analyzes differences of new media marketing and traditional marketing, lists main manifestation of the transformation of marketing mode of small and medium-sized enterprises in new media age and puts forward countermeasures for further transforming the marketing mode of small and medium-sized enterprises in new media age.
\end{abstract}

\section{Introduction}

The constant improvement of scientific and technological level in China has greatly promoted the development of various new media technologies. China has stepped into new media age. New media marketing mainly involving internet and mobile phone has developed well under the new situation of rapid development of new media marketing, thus making marketing tools and methods of small and medium-sized enterprises more diversified and complicated. Facing the fierce market competition, small and medium-sized enterprises must pay attention to new media marketing, master advantages of new media marketing, give play to its positive functions and satisfy demands of marketing strategies.

\section{Connotations of new media marketing}

As a marketing means emerging in recent years, new media marketing means that enterprises rely on modern digital new media such as internet and mobile phone to build their brand image. The essence of new media marketing is the replacement of big media broadcast by interpersonal communication with various participatory media. In information environment, the main operating management mode of enterprises - new media marketing - is also the most valuable business activity among electronic business activities of small and medium-sized enterprises. Its contents mainly cover online market survey, consumer behavior analysis and online promotion etc.

\section{Analysis on differences of new media marketing and traditional marketing}

New media marketing pays attention to the implementation of operation innovation and belongs to modern management means. It is one of the marketing modes with new media technology as main carrier, which continues and promotes the previous marketing mode. The new marketing mode - new media marketing - has significant differences from traditional marketing mode in marketing strategy, pricing mode and business model.

First, new media marketing puts consumer demand in the first place. It can master demands of consumers more accurately, timely and reliably through advantages of new media such as network, and develop products based on actual demands of consumers so as to satisfy individual requirements of various consumers. Due to various limitations in traditional marketing means, enterprises fail to 
master consumer demands accurately; therefore, they often put the production of products in the first place and put actual demands of consumers in a secondary place.

Second, new media marketing communication is uncontrollable. While implementing new media marketing, modern enterprises can make use of advertising information and news information, but cannot instill them into users independently or provide a lot of filtered information for consumers forcibly. On the contrary, audiences can dispose of different forms of marketing information through new media randomly whenever and wherever possible, publish information opposite to enterprises for counterattack by themselves and even send the information on the internet, thus producing influence on enterprise reputation. This means that everyone is a personal media and can be an important node of information transmission in new media age. This uncontrollable communication mode is one of the major differences between new media marketing and traditional marketing.

\section{Main performance of transformation of marketing mode of small and medium-sized enterprises in new media age}

With the great support of new media marketing, small and medium-sized enterprises have changed their marketing organization, program, tool and mode which become more and more complicated.

First, changes of marketing organization. Marketing organization model in the traditional sense is similar to pyramid, i.e. the general agency sells products to distributors who sell products to retailers who then sell products to consumers. Due to numerous marketing levels and untimely and inaccurate information feedback, it is difficult to adapt to the modern market environment with constant changes. Information transmission in the circumstance of new media marketing is realized in point-to-multipoint form. It can cause level change in marketing organization directly and reduce distribution level. Therefore, small and medium-sized enterprises can obtain the information fed back by consumers. In this way, the level of marketing organization, the number of sales employees and the number of direct selling stores reduce, thus causing the shortening of marketing channel of enterprises. It is very urgent to establish a corresponding new marketing organization.

Second, changes of marketing program. Marketing program in the traditional sense is advertisement in traditional media such as broadcast, television and newspaper. It can transmit relevant information to audiences unilaterally, obtain users' feedback by various means and understand their urgent demands. Among marketing programs of small and medium-sized enterprises in the traditional sense, advertisement marketing and information collection are simultaneous and uncrossed. They are separated in action. Due to multiple sales levels, small and medium-sized enterprises cannot establish a reasonable and effective marketing program. However, the interaction between small and medium-sized enterprises and audiences is two-way and synchronous in the process of new media marketing. Small and medium-sized enterprises can obtain the information fed back by audiences and audiences will search for information of various products of small and medium-sized enterprises positively and actively so that small and medium-sized enterprises can understand their demands more timely and establish a marketing program that is more personalized and pertinent and can meet consumer demands.

Third, changes of marketing tool. Marketing tools in the traditional sense mainly include broadcast, television and newspaper. However, new media marketing tools include website, forum, microblog, wechat, e-mail, online news release and search engine etc., among which news release and wechat are most commonly used and have ideal effects.

Forth, changes of marketing mode. Traditional marketing modes of small and medium-sized enterprises include experiential marketing, emotional marketing, knowledge marketing and differentiated marketing. Experiential marketing is a marketing means most commonly used by small and medium-sized enterprises. Consumers can go to stores directly to experience products and services of enterprises. Marketing modes above have produced new approaches which are more convenient in the new age of new media marketing. Each form has been widely used and produced ideal marketing effects. For example, Lenovo used the topic - distance of remembering when introducing a cloud video storage service produced by it, which drew wide attention in wechat and 
microblog and won the approval of audiences successfully with emotional marketing strategy. Meanwhile, hunger marketing mode adopted by mobile phone enterprises such as MI and APPLE also has good effects. Small and medium-sized enterprises in China should get inspiration from new media marketing modes of large enterprises so as to adjust their marketing strategies rationally and achieve magnificent turning.

\section{Countermeasures for further transforming marketing mode of small and medium-sized enterprises in new media age}

\section{Deepen the understanding of marketing concept in new media age}

The emergence of new media provides good opportunities for timely communication between small and medium-sized enterprises and consumers. Small and medium-sized enterprises should attach importance to the establishment and deepening of marketing concept in new media age because consumers are always the center of sales section and play a dominant role in all marketing activities in the process of new media marketing. Consumers can obtain various information of enterprises that they are interested in by using various new media methods, including product information, screen all information independently, read the information they are interested in and interact with small and medium-sized enterprises with new media means. New media marketing workers should attach great importance to information feedback work, collect and organize various information of consumers in time and feed back such information to the headquarters, and then communicate with consumers in time so as to make consumers realize their important value sincerely and actually achieve the consumer-centered marketing concept in new media age.

Implement reform and innovation of marketing mode of small and medium-sized enterprises continuously

With marketing means in the traditional sense, enterprises often carry out advertising publicity through media or conduct door-to-door selling and rely on many distribution channels so as to get the attention of consumers. Currently, the effect of marketing modes in the traditional sense has reduced greatly. After the occurrence and development of new media, the initiative and control power of market have been gradually transferred to consumers and media transmission forms have changed. It is inevitable to reform and innovate marketing modes. With the emergence of various new advertising forms and marketing means such as reverse communication, oral communication, accurate expression and event marketing in recent years, the reform and innovation of new media marketing of small and medium-sized enterprises focus on how to strengthen the interaction and communication with consumers by using features of new media so as to understand and serve them better and satisfy their demands. Obviously, this reform on traditional marketing means is not easy for many enterprises; however, it must be implemented. This requires innovative actions in communication countermeasure and marketing means.

\section{Establish high-quality new media marketing talent team}

New media marketing has self-evident significance for the development of small and medium-sized enterprises. New media marketing must be implemented under the premise of a complete marketing network. Small and medium-sized enterprises must focus on strengthening the establishment of network infrastructure in the process of marketing, greatly promote the information construction process of small and medium-sized enterprises, update relevant information on the website in time, feed back information demands of customers and strengthen the construction and management of new media marketing institutions so as to intensify the establishment of new media marketing network system continuously, form a complete new media network working mechanism finally and actually improve the effective capture rate of consumers. New media marketing is an innovative activity of marketing management on this basis and a professional talent team with modern marketing quality is required badly. Small and medium-sized enterprises should continue to improve the modern information awareness of marketing personnel and strengthen their technical training so that they can use new media technologies skillfully and provide customers with the latest and maturest product information in the rapidest way after receiving customer information, 
meanwhile build a new blueprint for future enterprise development and further improve the efficiency of new media marketing.

\section{Make combined use of new media skillfully}

Anything has two sides. Small and medium-sized enterprises should see both advantages and disadvantages when choosing new media. Due to mature development of traditional media, advertisers can understand their advantages and disadvantages very easily. However, modern people are often persuaded by the low price, rapid promotion and strong applicability of new media and neglect their advantages very easily. Small and medium-sized enterprises must pay attention to this in the specific operation. Generally speaking, new media have a poorer stability and higher risk degree compared to traditional media. Small and medium-sized enterprises must consider the influence of stability of new media marketing on their operation. Therefore, the author suggests that small and medium-sized enterprises should consider marketing price, influential power and influence on the reputation of enterprises comprehensively when delivering new media advertisement. This requires the combination of new media and traditional media. First, it is required to consider the economical efficiency of this combination, i.e. this combination must have a higher output than the use of a single media. Second, it is required to pay attention to the tridimensional character of the combination. Generally, the use of a single media or a kind of media can achieve uniform results but weak communication effect. The mutual supplement of various kinds of media can form a tridimensional marketing structure and achieve objectives of information transmission among enterprises. Third, enterprises should consider the complementarity when determining media so as to achieve the supplement and improvement of effects through the combination.

\section{Strengthen close cooperation with the government}

The state should provide great policy support for new media marketing. Each department should strengthen the guidance over small and medium-sized enterprises. Meanwhile, small and medium-sized enterprises should strive for necessary support of relevant government sectors positively and impel them to establish relevant laws and regulations, such as tax collection and intellectual property protection. The issuance of laws and regulations above can standardize market behaviors of enterprises more effectively and be conducive to building a healthy, harmonious and easy environment for the marketing of small and medium-sized enterprises in new media age.

\section{Conclusions}

In conclusion, the marketing of small and medium-sized enterprises in new media age has become a new marketing mode with distinctive features. It is different from enterprise marketing mode in the traditional sense. New media marketing is not single network advertising. It should provide interactive, accurate and creative marketing space for customers under the premise of high exposure rate. As new media has more and more profound influence on the consumption concept of modern people, marketing in new media age is becoming more and more important in the management of small and medium-sized enterprises. Therefore, small and medium-sized enterprises in new media age should be good at using new media marketing means so as to provide better services for brand creation and marketing and achieve good economic and social benefits of marketing communication.

\section{References}

[1] Chen Bo. Brief Analysis on Implementation of New Media Marketing Countermeasures by Enterprises. China Business \& Trade, 2010 (16).

[2] Zhao Yaofang. Research on Transformation of Marketing Strategies of Small and Medium-sized Enterprises in New Media Environment. Chinese and Foreign Entrepreneurs, 2012 (10).

[3] Wang Kejia. Discussions on New Media Marketing Strategies in Information Era. Communication and Copyright, 2013 (3). 
[4] Yan Xiang. Investigation and Analysis on Status of New Media Marketing in Small and Medium-sized Enterprises. Market Research, 2013 (9).

[5] Chen Bingjie. Discussions on Transformation of Marketing Mode of Small and Medium-sized Enterprises in New Media Age. Economic Forum, 2014 (6). 